\title{
Thermal Barrier Properties of Nonwovens Multilayer Struc- tures Investigated by Infrared Thermography
}

\author{
by M. Michalak ${ }^{1}$, B. Więcek ${ }^{2}$, I. Krucińska ${ }^{1}$, M. Lis ${ }^{2}$ \\ ${ }^{1}$ Department of Textile Metrology, Technical University of Łódź. Poland \\ ${ }^{2}$ Institute of Electronics, Technical University of Łódź, Poland
}

\begin{abstract}
Thermal barrier properties of nonwovens multilayer structures manufactured from polypropylene, flax and hemp fibers measured using thermographic method is presented in this paper. We calculated temperature differences between two opposite sides of the sample in the same time using measurement system with infrared mirror in the dynamic conditions.
\end{abstract}

\section{Introduction}

Textile products can be used for everyday purposes (for example clothing) and for technical purposes. Clothing, which has a protective function, is being a barrier against adverse effects of environment on the human organism. The electromagnetic waves can be oft the source of adverse effects. In recent years as barrier products can also be used technical products.

There are several ranges of electromagnetic waves which have a negative effect on human organism. This is ultraviolet radiation, infrared radiation and microwave radiation. In works [1-3], results of studies referring to some textile materials manufactured from chemical and natural fibres in the above listed ranges of frequency are presented. The obtained results indicate that materials containing bast fibres have better barrier properties.

Different methods of investigation apply to each range of frequency. In this work barrier properties of the material in the range of infrared radiation were evaluated on the basis of temperature distribution.

We will also try to determine thermal parameters of the investigated materials by a new thermographic method. In textile materials sciences usually in order to determine thermoconductive features of flat textiles, contact methods are used. Traditional methods enable determination of thermal parameters in stationary conditions and in a very limited temperature range [4-6]. When textiles are used by a man as clothing, there is also interaction of the human organism and the textile product. $A$ textile product of low physiological comfort will generate phenomena adverse to the organism, such as increased temperature, excessive sweating etc. This in results, leads to changes in parameters of the environment that the textiles are in. It means that the results of measurements obtained in laboratory may differ considerably from the real conditions that the product is used in. Therefore it is very important to develop methods of investigating thermal features in dynamic conditions, directly on the user. So far there is no method which would enable studying thermoconductive properties of a material without contact with the elements of the measuring apparatus in the online mode, when the human organism is influenced by factors which further influence physiological comfort. In work [7] the first studies showing the influence that the type of raw material has on human body were carried out by means of a thermovision camera. 
The tests were carried out in static conditions. Their purpose was not quantitative evaluation of thermal conductivity of the material, but only visualization of the phenomenon. In further works [8-11] studies on barrier properties of textile materials in dynamic conditions were carried out. Among other methods, the one of a thermal wave $[9,10]$ was used. In work [11] the thermal properties between two opposite sides of fabrics were investigated by thermography method.

\section{Study material}

In the present work nonwoven textile materials of different composition were investigated. The nonwovens were manufactured by a needling technique, from polypropylene fibres (PP) and bast fibres, that is flax and hemp, marked as $L$ and $\mathrm{K}$ respectively. PP fibres and bast fibres are characterized by different values of electrical resistivity. This parameter was decisive for the modelling of nonwoven multi-layer structures which were to become a barrier product. Two types of polypropylene fibres, PP1 and PP2, were used in the studies.

Table 1 shows the study results for fibres that the nonwovens were manufactured from. Studies were conducted in accordance with the relevant Polish Standards.

Table 1. Parameters of fibres

\begin{tabular}{|c|c|c|c|}
\hline Fibre & Linear density, dtex & Length, $\mathrm{mm}$ & Resistance, $\Omega$ \\
\hline PP1 & 7 & 40 & $2.88 \cdot 10^{13}$ \\
\hline PP2 & 18 & 40 & $1.38 \cdot 10^{11}$ \\
\hline L & 36.5 & 38.3 & $6.7 \cdot 10^{9}$ \\
\hline K & 41 & 37.8 & $5.7 \cdot 10^{10}$ \\
\hline
\end{tabular}

A nonwoven of multilayer structure was manufactured from the selected fibres. The single layers in this nonwovens were webs from polypropylene and bast fibres. In order to facilitate manufacturing of the nonwovens, PP2 fibres were covered with special preparation increasing their electrical conductivity (see Table 1). In the first phase a blended web was made from both and PP2 fibres, of percentage composition 50/50. Further, uniform webs from PP1 fibres were made. The blended web manufactured in this way was then used for modelling of the multi-layer structure by the electrically conducting layer. Blended webs were then arranged in a properly selected way to uniform webs of polypropylene fibres. The number of polypropylene - bast webs determined the content of bast fibres in the nonwoven. The percentage was calculated with respect to mass. The arranged webs were then subjected to the needling process, with the number of needle punches $200 / \mathrm{cm}^{2}$.

For the purposes of this work 3 nonwoven variants were chosen: one nonwoven from polypropylene fibres and two nonwovens with bast fibre content. PP variant is the nonwoven consisting of 7 webs $\mathrm{PP}, \mathrm{PP} / \mathrm{L}$ variant - nonwoven in which the middle layer contains 3 blended webs from polypropylene and flax fibres and the two outer layers are 2 webs from PP fibres, and PP/K variant with the content of hemp fibres with the same layer arrangement as PP/L variant. The percentage of bast fibres in the volume of nonwoven PP/L and PP/K was $21.5 \%$. All variants had similar values of the surface mass (Mp), thickness (d) and air permeability (Pp). These properties are the most important for the use features of the manufactured material. Only the nonwovens containing hemp fibres were characterized by slightly higher air permeability. Electrical bulk resistance $(R)$ and thermal resistance $\left(R_{t}\right)$ of nonwovens were also investigated, as factors responsible for barrier properties of the product. The 
thermal resistance was measured with Alambeta meter. The results are shown in table 2.

Table 2. Nonwoven characteristics

\begin{tabular}{|c|c|c|c|c|c|}
\hline Fibre & $\mathrm{Mp}, \mathrm{g} / \mathrm{m}^{2}$ & $\mathrm{~d}, \mathrm{~mm}$ & $\mathrm{Pp}, \mathrm{dm}^{3} / \mathrm{m}^{2} \mathrm{~s}$ & $\mathrm{R}, \Omega$ & $\mathrm{R}_{\mathrm{t}}, \mathrm{W}^{-1} \mathrm{~K} \cdot \mathrm{m}^{2}$ \\
\hline $\mathrm{PP}$ & 255.5 & 5.3 & 280.4 & $2.1 \cdot 10^{12}$ & 90,97 \\
\hline $\mathrm{PP} / \mathrm{L}$ & 257.2 & 5.1 & 242.5 & $4.7 \cdot 10^{11}$ & 85,21 \\
\hline $\mathrm{PP} / \mathrm{K}$ & 256.1 & 5.3 & 318.3 & $4.0 \cdot 10^{11}$ & 91,73 \\
\hline
\end{tabular}

The results in the table show that introducing $1 / 5$ of bast fibres to the volume of nonwoven leads to decreasing of its electrical through resistance by about five times. The thermal conductivity across the nonwovens is equal for all investigated samples.

\section{Method of investigations}

The new investigation method has been developed (Fig. 1). The surface of one half of the sample was exposed to the thermal wave generator. The heat flux was transferred along the surface and then to the opposite side of the not heated area of the sample. On the line between the heated and not heated part of the sample, two specially prepared mirrors were placed, at an angle of $90^{\circ}$ to each other (Fig. 1). They were located in such a way, that registration of thermograms from the two opposite surfaces, was possible at the same time. The thermovision camera was placed on the line of the longitudinal axis of the sample. Signal from the camera was transmitted to the computer. In this way, it was possible to register temperature distribution on both surfaces of the sample - heated and not heated.

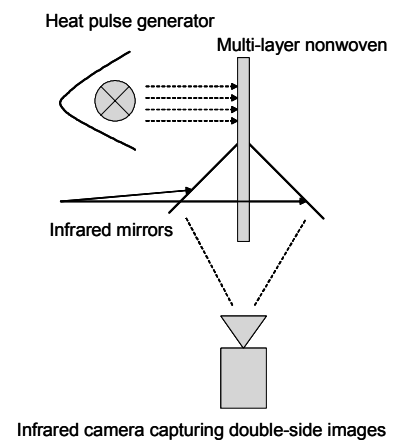

Fig. 1. Thermal measurement setup

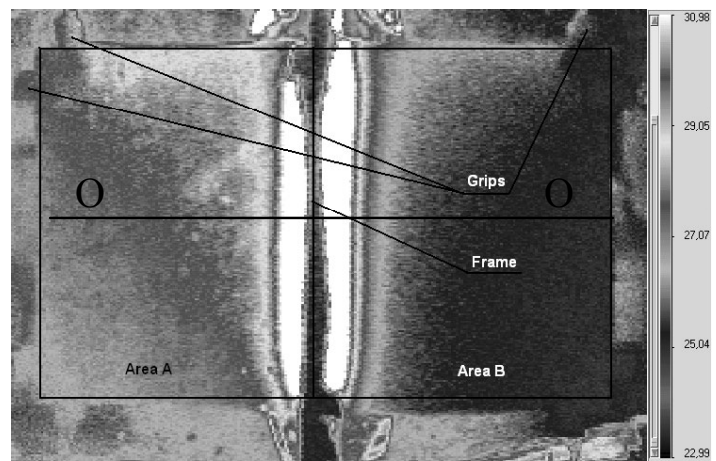

Fig. 2. Thermal images seen in the mirror

Analysis of the thermograms obtained from the mirror reflection ensures the temperature difference evaluation for points on the opposite surfaces of the sample. The measurements were performed with heat pulse excitation. The sample under investigation was fixed in specially constructed and prepared grips. The investigated samples were homogeneously strained with special plastic clamps. The distance of thermovision camera from the sample was $1000 \mathrm{~mm}$. Heater, mirrors and samples were insulated from environment. The exposure process consisted of two parts - 60 seconds of heating and 75 seconds of relaxation. During the measurements, thermal 
images were registered at the frequency of 1 frame/s and transferred to the computer memory and then analyzed. A sequence of 135 thermograms was acquired.

The example of thermogram from which the values of temperature on opposite sides of samples were registered and gradient of temperature was calculated is shown in Fig. 2. The values of temperature difference on the opposite sides of the samples were the factor, on the base of which the barrier properties of nonwovens under investigation were evaluated.

Non-homogenous distribution of temperature is caused by non-uniformity of investigated textile material.

\section{Results of investigations}

The temperature difference $(\Delta T)$ between points for time $t=60$ s after beginning of heating process, located on the line O-O shown in Fig. 2 for all investigated non woven multilayer structures is presented in Fig. 3.

Deviation of the temperature is due to nonuniformity textile material under investigations.

Mean value of temperature difference $(\Delta T)$ calculated on the border of the samples for $\mathrm{PP}, \mathrm{PP} / \mathrm{L}, \mathrm{PP} / \mathrm{K}$ variants is equal to $2.5{ }^{\circ} \mathrm{C}, 3.0{ }^{\circ} \mathrm{C}$ and $3.3{ }^{\circ} \mathrm{C}$, respectively.

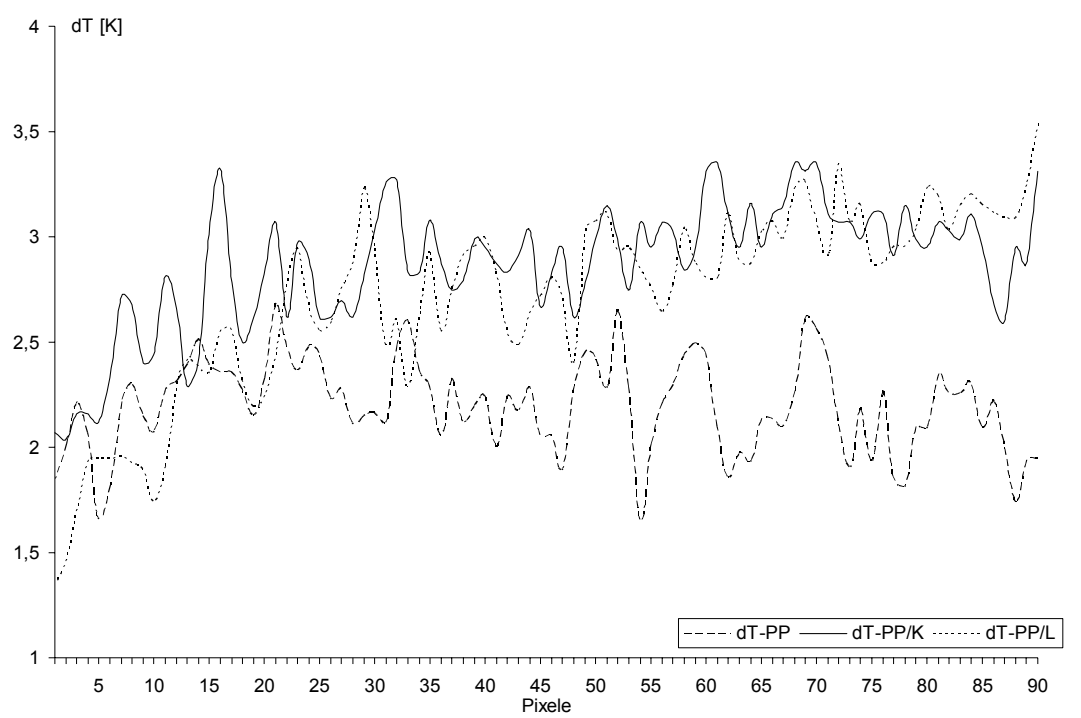

Fig. 3. Temperature difference on both sides of the nonwoven for $P P, P P / L, P P / K$ samples at $60 \mathrm{~s}$. of heating

Then, the analysis of temperature variation in time was performed. The calculations were carried out for pair of points $\mathrm{P} 1-\mathrm{P} 4, \mathrm{P} 2-\mathrm{P} 5$ and $\mathrm{P} 3-\mathrm{P} 6$, and the results are shown in Fig. 4. Below, the time distribution of temperature for points P3-P6 (Fig.4-5) is presented. In Fig. 4, 6, 8 points P1 - P6 are marked as 1-6.

The results for nonwoven polypropylene samples are presented in Fig. 4.

Similar results for PP/L and PP/K samples are presented in Fig. 6-7 and Fig 89 , respectively. 
The character of heating and cooling processes on side of the sample exposed to IR source in all investigated variants of nonwovens multilayer structures is different - the heating is faster, the cooling is slower.

The velocity of heating is the highest in samples with hemp and the lowest in nonwovens manufactured from polypropylene fibres.

The velocity of cooling process is the lowest for samples of polypropylene fibers.

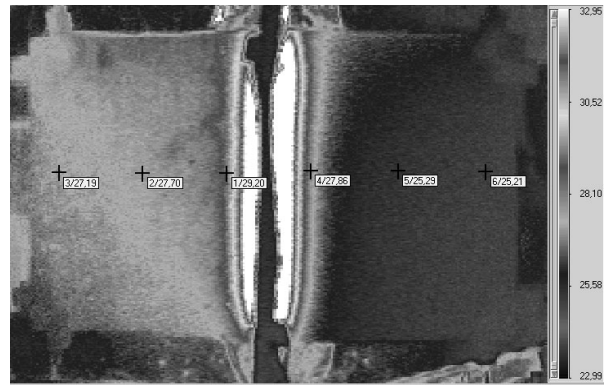

Fig. 4. Thermal image for $P P$ sample seen in the mirror at 60 s.

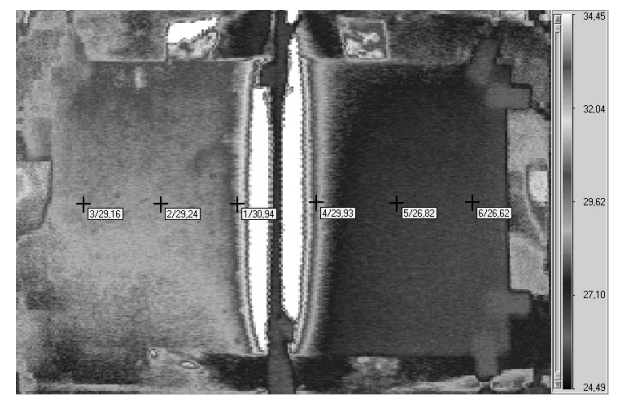

Fig. 6. Thermal image for $P P / L$ sample seen in the mirror at 60s.

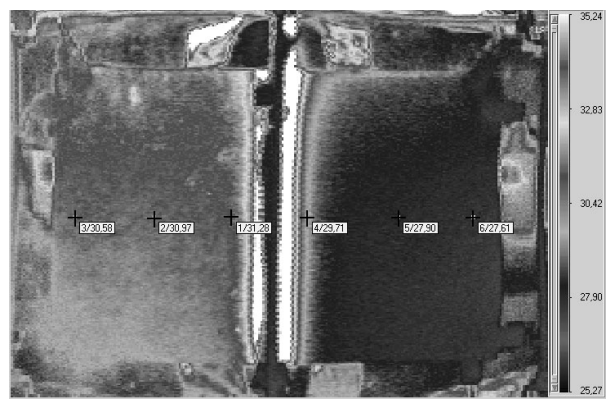

Fig. 8. Thermal image for PP/K sample seen in the mirror at 60 s.

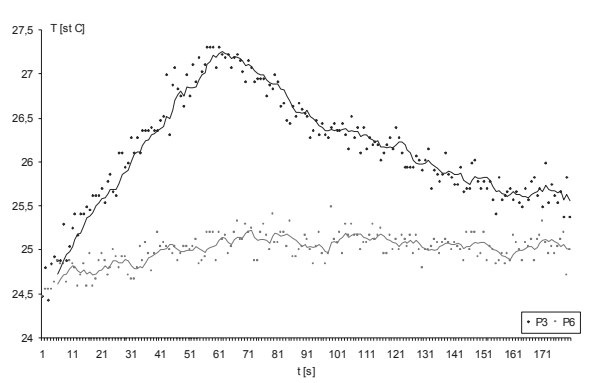

Fig. 5. Temperature in function of time for $P 3$ and $P 6$ points of $P P$ sample

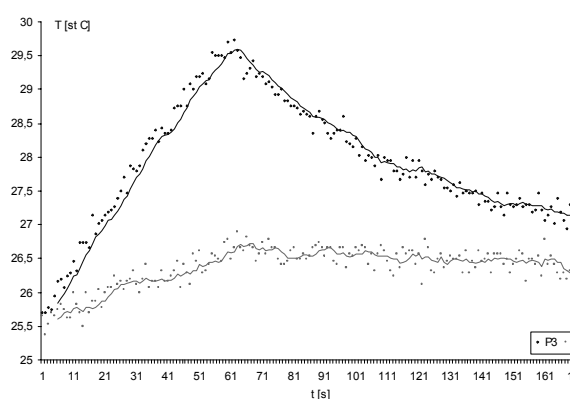

Fig. 7. Temperature in function of time for $P 3$ and $P 6$ points of $P P / L$ sample

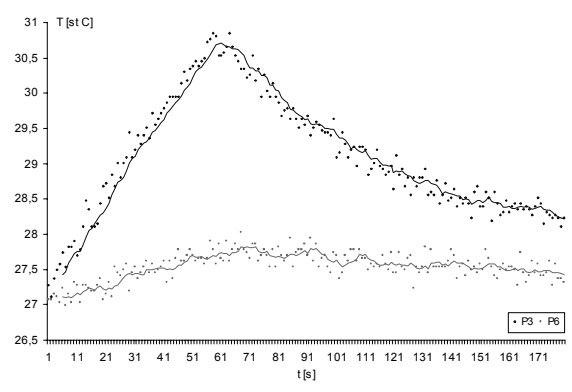

Fig. 9. Temperature in function of time for $P 3$ and $P 6$ points of $P P / K$ sample

The temperature on the side of samples exposed to infrared source is highest in nonwovens manufactured with hemp fibers and lowest in samples of PP fibers. 
The temperature distribution on opposite side is similar for all samples

The temperature difference between pair of points located near the heat source (P1-P4 ) at $60 \mathrm{~s}$. for $\mathrm{PP}, \mathrm{PP} / \mathrm{L}$ and $\mathrm{PP} / \mathrm{K}$ is $1.2^{\circ} \mathrm{C}, 1.3^{\circ} \mathrm{C}$ and $1.5^{\circ} \mathrm{C}$, respectively.

The temperature difference between points (P2-P5) at 60s. for PP, PP/L and $\mathrm{PP} / \mathrm{K}$ is $2.2^{\circ} \mathrm{C}, 2.7^{\circ} \mathrm{C}, 2.8^{\circ} \mathrm{C}$, respectively.

The temperature difference between points (P3-P6) at 60s. for PP, PP/L and $\mathrm{PP} / \mathrm{K}$ is $1.5^{\circ} \mathrm{C}, 2.7^{\circ} \mathrm{C}, 3.0^{\circ} \mathrm{C}$, respectively.

The calculations of temperature difference on another line as $\mathrm{OO}$ give another values, but in all cases the highest values of $\Delta T$ are for nonwovens with hemp fibres, and the lowest for nonwovens of polypropylene fibers.

\section{Conclusions}

- Polypropylene nonwovens cumulate heat more, i.e. it has higher thermal capacity

- The temperature difference between chosen points located on opposite surfaces of all investigated nonwoven multilayer structures is the highest in samples with hemp fibers.

- By temperature difference measurement it is possible to conclude, that nonwovens multilayer structures with hemp fibres have the best thermal barrier properties for infrared radiation.

- $\quad$ The presented results are preliminary, and the methodology requires further improvement.

\section{REFERENCES}

[1] R. Brazis, J. Czekalski, D. Kozakiewicz, M. Michalak, M. Stasiak: „Electromagnetic Wave Attenuation in Hemp-PAN Fibre Blends", Fibres \& Textiles in Eastern Europe, vol.8 Nr 2(29) 2000.

[2] M. Michalak, I. Krucińska. "Barrier Properties of Textiles with Hemp Fiber Components", II-nd Conference "Metrology in Textile Engineering" and I-st International Workshop Netecoflax - 2000 Lódź, 23 - 24 November 2000.

[3] W. Jędrzejewski. „Barrier properties of textile products \& UV radiation” „Właściwości barierowe wyrobów włókienniczych a promieniowanie UV”, Przegład Wlókienniczy, No 2, 2001.

[4] PN-86/P-04617 „Test methods for textiles. Thermoinsulating power. Determination of energy flux density" - "Metody badań wyrobów włókienniczych. Izolacyjność cieplna. Wyznaczanie gęstości strumienia energii.

[5] ISO 5085-1:1989 "Textiles - Determination of thermal resistance"

[6] Alambeta - The instruction of apparatus.

[7] M Zimniewska, M. Michalak, I. Krucińska, B. Więcek: "The comparison of the physical properties of the surface of clothing made from flax and polyester fibres". Updating the "cotonized" flax processing. Proceedings of the $2^{\text {nd }}$ International NETECOFLAX workshop, Universidade da Beira Interior, Covilha, Portugalia, Januar 2002.

[8] M. Michalak, I. Krucińska: "Barrier Properties of Textiles with Hemp Fiber Components", II-nd Conference "Metrology in Textile Engineering" and I-st International Workshop Netecoflax - 2000 Lódź, Poland, 23-24November, 2000.

[9] M. Michalak, B. Więcek, I. Krucińska: "Modelling and thermography measurements of thermal properties of nonwovens". $\mathrm{VI}^{\text {th }}$ Quantitative Infrared Thermography - QIRT 2002, Dubrovnik, Croatia, 28-30 September 2002. 
[10] M.Zimniewska, M. Michalak I. Krucińska, B. Więcek: "The physical properties of the surface of apparel made from flax and polyester fibres". Clothing Science and Technology, vol.15, No 3/4, 2003.

[11] M. Michalak, M Zimniewska, I. Krucińska, B. Więcek: "The Study of Thermal Properties of Linen/PES Fabrics using Thermovision methods". The $3^{\mathrm{d}}$ AUTEX Conference "World Textile Conference", Gdańsk, Poland, 25-27 Jun 2003. 